\title{
REPEATEDLY HEATED PALM KERNEL OIL INDUCES HYPERLIPIDEMIA, ATHEROGENIC INDICES AND HEPATORENAL TOXICITY IN RATS: THE BENEFICIAL ROLE OF VIRGIN COCONUT OIL SUPPLEMENTATION ${ }^{*}$
}

\author{
Ademola C. Famurewa ${ }^{1 凶}$, Onyebuchi E. Nwankwo², Abiola M. Folawiyo³, \\ Emeka C. Igwe ${ }^{4}$, Michael A. Epete ${ }^{4}$, Odomero G. Ufebe ${ }^{1}$ \\ 'Department of Medical Biochemistry, Federal University Ndufu-Alike Ikwo \\ Abakaliki, Ebonyi State, Nigeria \\ ${ }^{2}$ Department of Biological Sciences, Ebonyi State University \\ Abakaliki, Nigeria \\ ${ }^{3}$ Department of Physiology, Ebonyi State University \\ Abakaliki, Nigeria \\ ${ }^{4}$ Department of Anatomy, Ebonyi State University \\ Abakaliki, Nigeria
}

\begin{abstract}
Background. The literature reports that the health benefits of vegetable oil can be deteriorated by repeated heating, which leads to lipid oxidation and the formation of free radicals. Virgin coconut oil (VCO) is emerging as a functional food oil and its health benefits are attributed to its potent polyphenolic compounds. We investigated the beneficial effect of VCO supplementation on lipid profile, liver and kidney markers in rats fed repeatedly heated palm kernel oil (HPO).

Material and methods. Rats were divided into four groups $(n=5)$. The control group rats were fed with a normal diet; group 2 rats were fed a 10\% VCO supplemented diet; group 3 administered $10 \mathrm{ml} \mathrm{HPO} / \mathrm{kg}$ b.w. orally; group 4 were fed $10 \% \mathrm{VCO}+10 \mathrm{ml} \mathrm{HPO} / \mathrm{kg}$ for 28 days. Subsequently, serum markers of liver damage (ALT, AST, ALP and albumin), kidney damage (urea, creatinine and uric acid), lipid profile and lipid ratios as cardiovascular risk indices were evaluated.

Results. HPO induced a significant increase in serum markers of liver and kidney damage as well as concomitant lipid abnormalities and a marked reduction in serum HDL-C. The lipid ratios evaluated for atherogenic and coronary risk indices in rats administered HPO only were remarkably higher than control. It was observed that VCO supplementation attenuated the biochemical alterations, including the indices of cardiovascular risks.

Conclusion. VCO supplementation demonstrates beneficial health effects against HPO-induced biochemical alterations in rats. VCO may serve to modulate the adverse effects associated with consumption of repeatedly heated palm kernel oil.
\end{abstract}

Keywords: virgin coconut oil, palm kernel oil, atherogenic indices, hyperlipidemia

\footnotetext{
*This research work was self-funded by the authors included in the title page.

冈ademola.famurewa@funai.edu.ng
} 


\section{INTRODUCTION}

The widespread practice of using oil which has been repeatedly heated during food preparation is associated with a decrease in oil quality and the generation of free radicals ( $\mathrm{Ng}$ et al., 2014). It is reported in published papers that cooking oils undergo lipid oxidation when repeatedly heated and consuming such oils is associated with health impairment in humans and animals (Jaarin et al., 2011; Ng et al., 2014). It spoils the taste, smell and colour of the oil, but intake of the oil may also pose an unmitigated threat to health $(\mathrm{Ng}$ et al., 2014). The practice of reusing oil during food preparation is not only peculiar to household kitchens or roadside food stalls; established food outlets in large cities also use this method to reduce costs (Jaarin et al., 2011). Deep frying is the most common and one of the oldest methods of food preparation worldwide. It involves heating oil at a high temperature $\left(\geq 180^{\circ} \mathrm{C}\right)$, at the same time exposing the oil to moisture and air, thus triggering a vast array of chemical reactions collectively known as lipid oxidation (Laguerre et al., 2007; Zhang et al., 2012). Oxidative products, including peroxides, hydroperoxides, aldehydes and several other potentially hazardous non-volatile polar compounds, are deposited in cooking oil, compromising the biochemical and nutritional safety of the oil (Hur et al., 2005). Some of these products are absorbed into fried foods; the literature suggests that consuming fried food causes depletion of endogenous antioxidants and stimulates membrane lipid peroxidation (Jaarin and Kamisah, 2012). The repeated heating of cooking oil produces oil highly susceptible to lipid peroxidation. Peroxidation of biological systems is associated with a number of pathological manifestations. The health effects consuming repeatedly heated cooking oils on the antioxidant system, lipid metabolism, inflammation and cardiovascular homeostasis have been reported (Ng et al., 2014). Studies report that heated oils may increase the risk of cardiovascular diseases (CVD) by raising blood pressure, inducing oxidative stress, dyslipidemia and endothelial dysfunction (Adam et al., 2009; Ichihara, 2013; Ng et al., 2014; Xian et al., 2012). Adam et al. (2008) reports lipid abnormalities induced by chronic consumption of heated oil in ovariectomised rats. Considering the cytotoxic products of heated oil, its effects on major organs such as liver and kidney may not be insignificant. Previous studies report adverse effects of repeatedly heated oil on liver and lipid status (Latha et al., 2010; Srivastava et al., 2010). However, there is a lack of data on the effect of heated oil consumption on the liver and kidney even in experimental animals and the possible natural modalities for mitigation are not explored.

Nowadays, the consumption of foods laden with deep-fried oils is gaining popularity, which may increase the risk of obesity, CVDs and organ damage. Reusing heated oil appears to be an indispensable cooking habit, and the underlying motivation for this practice is to reduce the expense of food preparation. The need for dietary and non-pharmacological supplementation to mitigate the effects of toxicants from oxidized oils is important. Currently, the use of natural products and supplements to combat toxic agents and avert the course of disease is becoming more attractive both to the public and researchers, and has increased tremendously over the past three decades (Ekor, 2014). It is estimated that about $80 \%$ of people worldwide have applied natural medicines as primary health care (Ekor, 2014). Virgin coconut oil (VCO) is a natural product emerging as a functional food oil with health benefits reported in research papers. Virgin coconut oil is produced from coconut kernels by natural means with or without the application of heat and without chemical refining (Srivastava et al., 2016). Qualitative analysis reveals that VCO contains mainly medium-chain triacylglycerol and bioactive phenolic compounds beneficial to health through their scavenging free radicals and toxic oxidants (Marina et al., 2009). Previous reports have highlighted the experimental hepatoprotective (Famurewa et al., 2017), nephroprotective (Akinnuga et al., 2014) and hypolipidemic (Srivastava et al., 2013) effects of VCO. In view of this, there is a need for further research to develop understanding of the possible beneficial health effect of VCO.

The current study investigated the effect of administering repeatedly heated palm kernel oil on lipid profile, atherogenic indices, liver and kidney status and the possible role of dietary supplementation of VCO in rats. 


\section{MATERIALS AND METHODS}

\section{Animals}

Twenty male rats of the Wistar strain (160 to $190 \mathrm{~g})$ were used as experimental animals in the present investigation. The rats were kept in stainless steel cages and maintained with a 12:12-hour light/dark schedule at room temperature at the Animal House of the Department of Biochemistry, Ebonyi State University, Nigeria. All of the rats were provided with rat pellets (Vital Feeds Nigeria Limited, Jos, Nigeria) and water ad libitum for 28 days. The rats were acclimatized one week prior to treatment and were handled in a humane manner, in accordance with the approved animal experimental procedures of the NIH Guidelines for the Care and Use of Laboratory Animals (National..., 1985).

\section{Preparation of heated palm kernel oil (HPO)}

Fresh palm kernel oil was purchased from a local market in Abakaliki, Ebonyi State, and the HPO was prepared by the current investigators according to the method described by Owu et al. (1998). $500 \mathrm{~g}$ of sweet potato slices were fried in a stainless steel wok containing 2 litres of palm kernel oil for 10 minutes at $180^{\circ} \mathrm{C}$. The heating procedure was done once daily for 5 consecutive days. There was no subsequent addition of fresh oil between the daily frying processes to make up for the loss due to absorption by the fried potato.

\section{Preparation of the VCO supplemented diet}

The VCO was extracted using the wet extraction method according to Nevin and Rajamohan (2004). In brief, the viscous slurry obtained from coconut flesh (solid endosperm) was made into a creamy milky solution through the addition of about $400 \mathrm{ml}$ of fresh water. The solution was sieved through cheesecloth and the milky filtrate was left standing for $48 \mathrm{~h}$ to separate the creamy top and water layers. The top layer was carefully removed and subjected to mild heating $\left(50^{\circ} \mathrm{C}\right)$ to remove moisture. The floating oil was gently scooped out and filtered into an air-tight container. This oil thus prepared without refining, bleaching and deodorizing was used to prepare VCO diet fed to rats in the current study. The $10 \%$ VCO supplemented diet was prepared by mixing $90 \mathrm{~g}$ ground standard pellet with $10 \mathrm{~g} \mathrm{VCO}$ and kept in an airtight container.

\section{Experimental design}

Following 1 week of acclimatization, the rats were randomly divided into 4 groups $(n=5)$ and the treatment design was as follows:

- group 1 (normal control): received fresh water (orally, $5 \mathrm{ml} / \mathrm{kg}$ ) for 28 days

- group 2 (VCO control): received a $10 \%$ VCO supplemented diet for 28 days

- group 3 (HPO control): received $10 \mathrm{ml} \mathrm{HPO/kg}$ body weight of rat (orally) for 28 days

- group 4 (VCO + HPO): received a 10\% VCO diet $+10 \mathrm{ml} \mathrm{HPO} / \mathrm{kg}$ (orally) for 28 days.

The weight of the rats was determined and recorded at the beginning and end of the experimental period ( 28 days). At the end of the treatment period, all animals (fasted) were anaesthetized with ether and sacrificed to obtain blood collected via retro-orbital venous plexus by capillary tubes into plain sample bottles and allowed to clot. The clotted blood samples were centrifuged $(3000 \times \mathrm{g}$ for $15 \mathrm{~min})$ to separate the serum used for analysis of lipid profile, liver and kidney function markers.

\section{Biochemical analyses}

Biochemical measurements were carried out using standard commercially available kits. The liver function markers, alanine aminotransferase (ALT), aspartate aminotransferase (AST), alkaline phosphatase (ALP) and albumin (ALB) were analyzed in serum stored at $4^{\circ} \mathrm{C}$ using standard methods in commercial diagnostic kits by RANDOX Laboratories Ltd., UK, following the manufacturer's instructions. The kidney function markers, urea, uric acid and creatinine and lipid profile, total cholesterol (TC), triglyceride (TG), low-density lipoprotein cholesterol (LDL-C) and high-density lipoprotein cholesterol (HDL-C) were also analyzed in the serum using RANDOX kits.

\section{Cardiovascular risk indices}

The coronary risk index (CRI), atherogenic index (AI) and cardiovascular risk index (CVRI) were determined using the following formulae (Abbott et al., 1988; Alladi et al., 1989).

Atherogenic index $(\mathrm{AI})=\mathrm{LDL}$ cholesterol $/ \mathrm{HDL}$ cholesterol 
Coronary risk index $(\mathrm{CRI})=$ total cholesterol / HDL cholesterol

Cardiovascular risk index $(\mathrm{CVRI})=$ triglyceride $/ \mathrm{HDL}$ cholesterol

\section{Statistical analysis}

The results were expressed as mean \pm standard error of mean. Statistical differences were determined by analysis of variance (ANOVA) followed by Tukeys' Post Hoc Test. All analyses were performed using the SPSS version 22.0 for Windows (SPSS Inc., Chicago, IL, USA), and $p<0.05$ was considered statistically significant.

\section{RESULTS}

\section{The effect of VCO supplementation on the body weight of rats}

Table 1 presents the effect of VCO supplementation on body weight of HPO-administered rats after 28 days.
It was observed that the supplementation of VCO or HPO failed to exert a significant $(p>0.05)$ change in body weight compared to the control. Similarly, the effect of VCO supplementation on the body weight of rats administered HPO was insignificant $(p>0.05)$ compared to the HPO group.

\section{Effect of VCO on serum liver function markers of HPO-administered rats}

The effect of VCO on liver enzyme markers and albumin in HPO-administered rats is shown in Table 2. We found that the serum activities of ALT, AST, ALP and albumin level in rats fed $10 \%$ VCO only were comparable to the control $(p>0.05)$. Conversely, administration of HPO significantly increased $(p<0.05)$ serum activity of ALT along with a marked decrease in level of albumin when compared with the control. However, a $10 \%$ VCO supplemented diet significantly decreased ALT and AST activity, as well as producing a significant increase in albumin.

Table 1. The effect of VCO supplementation on the body weight of HPO-administered rats, $g$

\begin{tabular}{lllc}
\hline \multicolumn{1}{c}{ Group } & Initial weight & Final weight & Change in weight \\
\hline Control & $185.6 \pm 13.2$ & $201.5 \pm 4.3$ & $23.6 \pm 12.4$ \\
$10 \% \mathrm{VCO}$ & $171.9 \pm 15.6$ & $199.5 \pm 2.7$ & $27.7 \pm 9.3$ \\
$10 \mathrm{ml} \mathrm{HPO} / \mathrm{kg}$ & $179.9 \pm 6.3$ & $202.3 \pm 2.7$ & $25.5 \pm 8.3$ \\
$\mathrm{VCO}+\mathrm{HPO}$ & $181.1 \pm 3.47$ & $206.8 \pm 3.2$ & $25.9 \pm 2.3$ \\
\hline
\end{tabular}

VCO - virgin coconut oil, HPO - heated palm kernel oil.

The results are expressed as mean $\pm \operatorname{SEM}(n=5), P<0.05$.

Table 2. The effect of VCO on the serum liver function markers (ALT, AST, ALP and ALB) of HPO-administered rats

\begin{tabular}{lcccc}
\hline \multicolumn{1}{c}{ Group } & ALT, U/L & AST, U/L & ALP, U/L & ALB, g/dl \\
\hline Control & $498.9 \pm 31.7$ & $492.6 \pm 31.8$ & $141.2 \pm 22.35$ & $3.32 \pm 0.11$ \\
$10 \% \mathrm{VCO}$ & $534.2 \pm 66.3$ & $513.8 \pm 60.4$ & $115.1 \pm 9.2$ & $3.14 \pm 0.20$ \\
$10 \mathrm{ml} \mathrm{HPO} / \mathrm{kg}$ & $618.0 \pm 31.2^{*}$ & $566.9 \pm 20.9$ & $160.8 \pm 21.2$ & $2.28 \pm 0.15^{*}$ \\
$\mathrm{VCO}+\mathrm{HPO}$ & $456.7 \pm 19.5^{\#}$ & $411.8 \pm 28.9^{\#}$ & $161.7 \pm 25.5$ & $3.13 \pm 0.22^{\#}$ \\
\hline
\end{tabular}

VCO - virgin coconut oil, HPO - heated palm kernel oil.

The results are expressed as mean $\pm \operatorname{SEM}(n=5)$.

${ }^{*} p<0.05$ - significantly different compared to the control.

${ }^{\#} p<0.05-$ significantly different compared to the HPO group. 


\section{Effect of VCO on serum kidney function markers of HPO-administered rats}

Table 3 shows the effect of VCO supplementation on kidney function markers in HPO-administered rats. Administration of HPO demonstrated induction of nephrotoxicity by significant $(p<0.05)$ increases in serum levels of urea, creatinine and uric acid compared to the control. However, VCO supplementation prevented the HPO-induced nephrotoxicity evident by prominent decreases $(p<0.05)$ in urea, creatinine and uric acid in comparison to the HPO control group.

\section{Effect of VCO on serum lipid profile parameters in HPO-administered rats}

Table 4 shows the results obtained as the effect of VCO supplementation on serum levels of TC, TG,
LDL-C, and HDL-C in rats administered HPO. Supplementation of $10 \%$ VCO to normal rats produced a non-significant $(p>0.05)$ effect on serum levels of TC, TG, LDL-C, and HDL-C. However, administration of HPO to normal rats significantly $(p<0.05)$ increased serum levels of TC, TG, and LDL-C, with a concomitant marked decrease in the serum level of HDL-C. Interestingly, it was observed that VCO supplementation to rats administered HPO reversed the lipid abnormalities induced by HPO.

\section{The effect of VCO on cardiovascular risk indices in HPO-administered rats}

The effects of VCO on the atherogenic index (AI), coronary risk index (CRI) and cardiovascular risk index (CVRI) are shown in Figure 1, 2 and 3 respectively.

Table 3. The effect of VCO on serum kidney function markers (urea, creatinine and uric acid) of HPO-administered rats

\begin{tabular}{lccc}
\hline \multicolumn{1}{c}{ Group } & Urea, $\mathrm{mmol} / \mathrm{L}$ & Creatinine, $\mu \mathrm{mol} / \mathrm{L}$ & Uric acid, $\mathrm{mmol} / \mathrm{L}$ \\
\hline Control & $6.78 \pm 0.45$ & $48.0 \pm 3.8$ & $0.125 \pm 0.250$ \\
$10 \% \mathrm{VCO}$ & $8.34 \pm 0.78$ & $54.1 \pm 4.2$ & $0.10 \pm 0.001$ \\
$10 \mathrm{ml} \mathrm{HPO} / \mathrm{kg}$ & $11.02 \pm 1.47^{*}$ & $76.8 \pm 15.2^{*}$ & $0.20 \pm 0.029^{*}$ \\
$\mathrm{VCO}+\mathrm{HPO}$ & $8.75 \pm 0.69^{\#}$ & $49.0 \pm 1.75^{\#}$ & $0.10 \pm 0.001^{\#}$ \\
\hline
\end{tabular}

VCO - virgin coconut oil, HPO - heated palm kernel oil.

The results are expressed as mean $\pm \operatorname{SEM}(n=5)$.

${ }^{*} p<0.05$ - significantly different compared to the control.

${ }^{\#} p<0.05$ - significantly different compared to the HPO group.

Table 4. The effect of VCO on serum lipid profile parameters (TC, TG, LDL-C, and HDL-C) in HPO-administered rats, $\mathrm{mmol} / \mathrm{L}$

\begin{tabular}{lcccc}
\hline \multicolumn{1}{c}{ Group } & \multicolumn{1}{c}{ TC } & TG & LDL-C & HDL-C \\
\hline Control & $2.18 \pm 0.01$ & $2.62 \pm 0.42$ & $0.65 \pm 0.41$ & $1.55 \pm 0.03$ \\
$10 \% \mathrm{VCO}$ & $2.34 \pm 0.18$ & $2.10 \pm 0.11$ & $0.66 \pm 0.29$ & $1.58 \pm 0.13$ \\
$10 \mathrm{ml} \mathrm{HPO} / \mathrm{kg}$ & $3.49 \pm 0.19^{*}$ & $3.20 \pm 0.19^{*}$ & $1.45 \pm 0.17^{*}$ & $0.76 \pm 0.24^{*}$ \\
$\mathrm{VCO}+\mathrm{HPO}$ & $2.05 \pm 0.23^{\#}$ & $2.05 \pm 0.22^{\#}$ & $0.68 \pm 0.27^{\#}$ & $1.39 \pm 0.12^{\#}$ \\
\hline
\end{tabular}

VCO - virgin coconut oil, HPO - heated palm kernel oil.

The results are expressed as mean $\pm \operatorname{SEM}(n=5)$.

${ }^{*} p<0.05$ - significantly different compared to the control.

${ }^{\#} p<0.05-$ significantly different compared to the HPO group. 


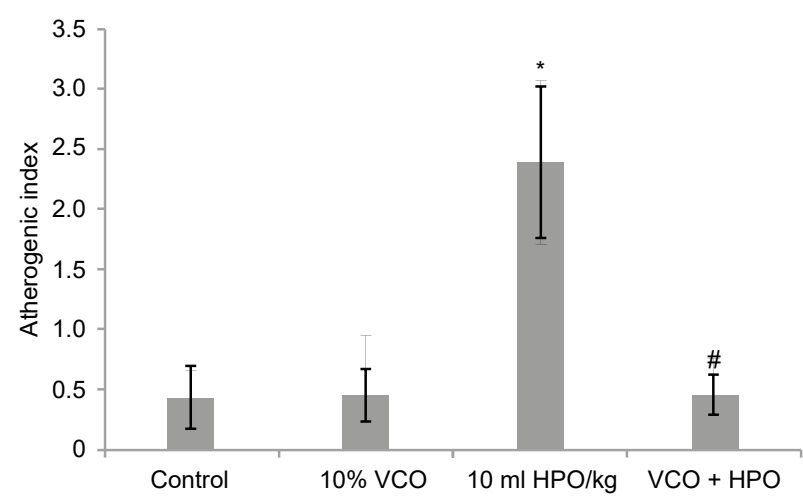

Fig. 1. The effect of virgin coconut oil (VCO) on the atherogenic index of rats fed with heated palm kernel oil (HVO). The results are expressed as mean $\pm \operatorname{SEM}(n=5): * p<0.05-$ significantly different compared to the control, $\# p<0.05-$ significantly different compared to the HPO group

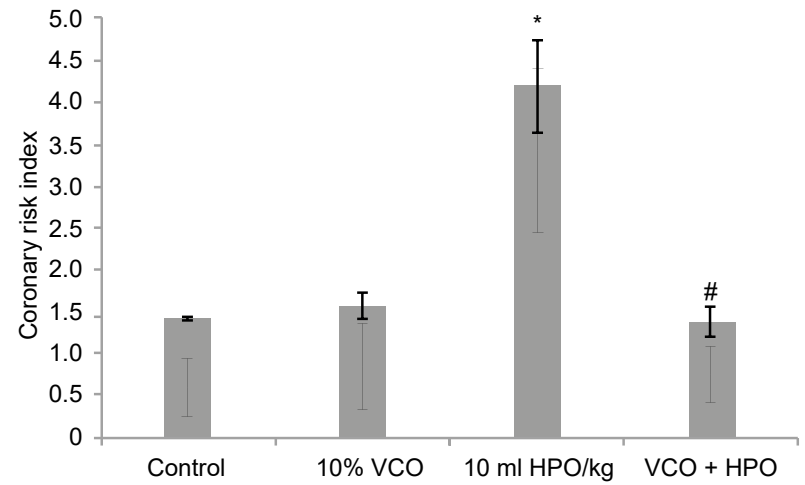

Fig. 2. The effect of virgin coconut oil (VCO) on the coronary risk index of rats fed with heated palm kernel oil (HVO). The results are expressed as mean \pm SEM $(n=5)$ : ${ }^{*} p<0.05-$ significantly different compared to the control, $\# p<0.05$ - significantly different compared to the HPO group

Repeatedly heated palm kernel oil (HPO group) significantly increased AI, CRI and CVRI in comparison to the control. Meanwhile, the $10 \%$ VCO supplementation attenuated the increase in $\mathrm{AI}, \mathrm{CRI}$ and CVRI comparable to the control.

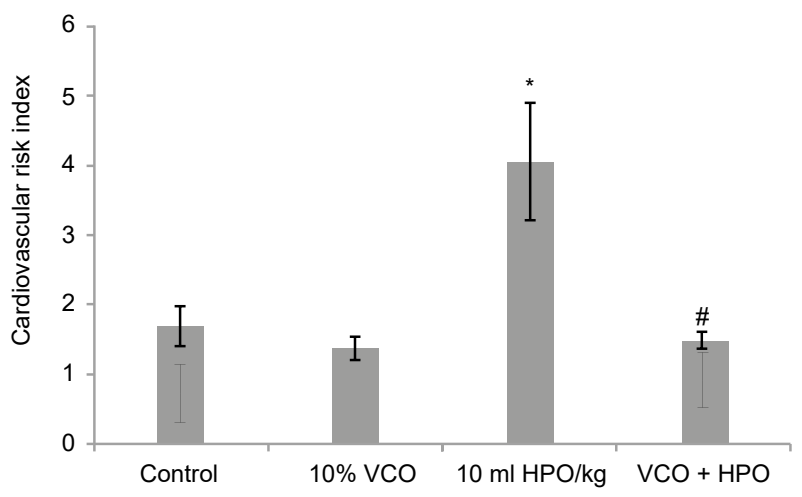

Fig. 3. The effect of virgin coconut oil (VCO) on the cardiovascular risk index of rats fed with heated palm kernel oil (HVO). The results are expressed as mean $\pm \operatorname{SEM}(n=5)$ : ${ }^{*} p<0.05-$ significantly different compared to the control, $\# p<0.05-$ significantly different compared to the HPO group

\section{DISCUSSION}

The thermal effects on the safety and suitability of edible oils have drawn tremendous attention from investigators worldwide. The heating effect diminishes bioactive compounds and beneficial fatty acids present in vegetable oil, although public awareness of this is very shallow and not always considered (Abdullah et al., 2010; $\mathrm{Ng}$ et al., 2014). Because recycling frying oil is still widely practised in the society, and as its chronic consumption may promote cardiovascular disease development, it is therefore important to consider strategies amenable to daily diet to mitigate the associated adverse health effects (Rashid et al., 2013).

In the present study, it was shown that heated palm kernel oil (HPO) induces hepatic and renal damage. We found that liver damage markers, ALT, AST and ALP activities were higher with a concomitant lowered level of albumin compared to the control, although only ALT activity and serum albumin were significantly altered in the current study. The damaged structural integrity of the liver increases serum levels of transaminases ALT and AST and ALP, because they are usually found in cytosol and released into circulation during hepatocellular damage (Kalantari et al., 2014). The liver is a delicate organ susceptible to damage by exogenous toxicants, and liver enzymes are good indicators for liver status assessment (Mourya 
et al., 2017). However, peroxides and hydroperoxides are well-known free radicals reported in previous studies to be deposited in heated cooking oils. Free radical generation depresses antioxidant mechanisms and contributes to lipid peroxidation and oxidative stress development. Rats that were fed heated oil showed increased oxidative stress and lipid peroxidation in plasma, heart and liver tissues (Srivastava et al., 2010; Subermaniam et al., 2014). Although the current study has not estimated oxidative stress indicators, oxidative stress promotes lipid peroxidation of the hepatocyte membrane, which may be involved in liver damage and causes enzyme release into the circulation. Furthermore, report findings from earlier investigations have implicated lipid peroxidation and oxidative stress in the pathogenesis of endothelial dysfunction, hypertension and cardiovascular diseases induced by prolonged consumption of repeatedly heated oils (Jaarin et al., 2011; Ng et al., 2014; Yen et al., 2010). Evidence suggests elevated plasma lipid peroxidation content in rats fed oil heated five times (Jaarin and Kamisah, 2012). The results hereby agree with a previous study reported by Yen et al. (2010) that deep-frying oil fed to rats markedly increased ALT, whereas no appreciable effect found on AST. Owu et al. (1998) report a significant increase in ALT, although, contrary to our findings, chronic consumption of thermally oxidized palm oil induced a significant increase in AST and ALP in the rats. However, VCO supplementation retarded the liver damage in rats fed HPO for 28 days in this study (Table 2). The serum liver enzyme activities were remarkably reduced to levels comparable to the control. The beneficial effect of VCO supplementation found in the current study corroborates earlier reports regarding VCO. Virgin coconut oil supplementation prevents lipid peroxidation in the cardiac tissue of rats fed heated palm oil (Subermaniam et al., 2014). Recent experimental studies have indicated the hepatoprotective potential of VCO supplementation in animal models (Famurewa et al., 2017; Otuechere et al., 2013). In fact, a recent study by Kamisah et al. (2015) demonstrated the VCO cardioprotective effect in heated palm oil diet-induced hypertensive rats. There is a strong suggestion that the mechanism underlying the beneficial health effects of VCO is associated with major bioactive phenolic compounds, such as ferulic and $p$-coumaric acids in VCO
(Marina et al., 2009). Ferulic and $p$-coumaric acids are phenolic acids reported to possess potent antioxidant and anti-inflammation properties (Marina et al., 2009). The free radical scavenging properties of ferulic and $p$-coumaric acids could contribute to hepatocyte stabilization in this study.

To our knowledge, reports on the biochemical effect of heated oil on the kidneys are very scarce in the published literature. The administered HPO had a nephrotoxic effect on the kidney evidenced by the prominent increases in serum levels of urea, uric acid and creatinine in the present study. The kidneys play a key role in the excretion of metabolites, regulation of extracellular fluid volume, electrolyte composition and acid-base balance (Kalantar et al., 2016). Toxic influences on the kidneys may compromise these functions, resulting in waste accumulation in circulation. Urea, uric acid and creatinine are indicators for kidney status and renal structural integrity. In our study, significantly raised levels of renal markers in HPO-fed rats compared to normal control rats showed renal toxicity. This elevation in the renal marker levels could be due to kidney tubule injury induced by oxidative toxicants from the HPO. Shastry et al. (2011) report histopathological changes in the kidneys of rats fed heated sunflower oil and palm oil after 8 weeks, while Yen et al. (2010) report an insignificant effect of deep-frying oil on creatinine excretion. However, the current report represents the possible deleterious effect of repeatedly heated palm kernel oil (HPO) on the kidneys. Interestingly, supplementation of $10 \% \mathrm{VCO}$ attenuated the nephrotoxic effect of HPO by preventing a rise in the levels of markers of renal damage. VCO is a natural functional food oil containing ferulic and $p$-coumaric acids as major bioactive phenolic compounds. It was recentlyshown that VCO supplementation prevents cyclophosphamide-induced nephrotoxicity in mice via antioxidant mechanism attributed to free radical scavenging activity of VCO (Nair et al., 2016).

Several researchers have found that cardiovascular protective benefits of vegetable oils deteriorate when oils are repeatedly exposed to extreme temperatures, moisture and air during food preparation, particularly in deep-fat frying ( $\mathrm{Ng}$ et al., 2014). These findings are based on the effects of repeated heating on oils, including increased fatty acid instability and saturation, hyperlipidemic activity and depreciated level of 
tocopherols that protect biological membranes against oxidative and carcinogenic stress (Falade et al., 2015; Jaarin and Kamisah, 2012). Oxidized lipids in heated oil acquire undesirable properties associated with saturated fatty acids to promote correlation with increased serum cholesterol levels and higher LDL-cholesterol in particular (Jaarin et al., 2011). In the present study, the rats that were fed with HPO displayed remarkably increased serum TC, TG, LDL-C with a decreased level of HDL-C. The data presented here (Table 4) suggest that HPO treatment may perturb lipid metabolism in favour of dyslipidemia without any significant effect on the body weight of rats. Our results are concordant with the first study to describe the harmful effect of heated vegetable oil on blood pressure and lipid profile (Osim et al., 1996). This study reports considerable changes in the plasma lipid profile of rats following chronic consumption of a 15\%-oxidized palm oil diet compared to the control. Here, we have reported considerable changes in the serum lipid profile of rats following sub-chronic administration of a $10 \%$ repeatedly heated palm kernel oil diet compared to the control. Elevated levels of serum TC, TG, LDL-C and VLDL-C with a concomitant decrease in serum HDL-C levels are useful indicators of dyslipidemia, atherosclerosis, and coronary artery disease. Lipid abnormalities are a well-known risk factor for CVD. Evidence indicates that increased LDL-C and decreased HDL-C levels are associated with a higher risk of CVD ( $\mathrm{Ng}$ et al., 2014). These changes in lipids, as observed in this study and previously established in rats, could predispose to the risk of atherosclerosis and cardiovascular disease development (Ajiboye et al., 2016). Moreover, for decades, lipid profile was of profound importance for determining the cardiovascular risk. Currently, the use of lipid ratios is being considered to provide information on the optimization of the predictive capacity of lipid profiles in CVD risk assessment (Gasevic et al., 2014). Assessment of lipid ratios or cardiovascular risk indices, $\mathrm{LDL}-\mathrm{C} / \mathrm{HDL}-\mathrm{C}(\mathrm{AI})$, total cholesterol (TC)/HDL-C (CRI) and TG/HDL-C (CVRI) are reported in the present study. The evaluated indices, AI, CRI and CVRI were significantly elevated compared to the control (Figs. 1 to 3). However, VCO supplementation evidently reversed the lipid profile changes, as well as atherogenic indices. In consonance with our result, the antidyslipidemic activity of VCO has been shown in experimental diabetes- and cholesterolinduced dyslipidemia (Akinnuga et al., 2014; Nevin and Rajamohan, 2009). The reversal of HPO-mediated hyperlipidemia in serum by a $10 \%$ VCO diet could be due to the presence of antihyperlipidemic activity of VCO, for which polyphenolic compounds stand out (Jaarin et al., 2014).

\section{CONCLUSION}

Taken together, consumption of repeatedly heated palm kernel oil demonstrated adverse effects on biochemical and atherogenic indices in rats. The present study shows for the first time that VCO supplementation could mitigate the deleterious effect of repeatedly heated palm kernel oil in rats. However, further studies should explore the mechanism underlying the beneficial effect of VCO.

\section{REFERENCES}

Abbott, R. D., Wilson, P. W., Kannel, W. B., Castelli, W. P. (1988). High density lipoprotein cholesterol, total cholesterol screening and myocardial infarction. The Framingham Study. Arteriosclerosis, 8, 207-211.

Abdullah, A., Shahrul, S., Chan, X. S., Noorhazliza, A. P., Khairunnisak, M., Qodriyah, H.M., ..., Kamsiah, J. (2010). Level of awareness amongst the general public regarding usage of repeatedly heated cooking oil in Kuala Lumpur, Malaysia. Inter. Med. J., 17(4), 310-311.

Adam, S. K., Das, S., Jaarin, K. (2009). A detailed microscopic study of the changes in the aorta of experimental model of postmenopausal rats fed with repeatedly heated palm oil. Int. J. Exp. Pathol., 90(3), 321-327.

Adam, S. K., Das, S., Soelaiman, I. N., Umar, N. A., Jaarin, K. (2008). Consumption of repeatedly heated soy oil increases serum parameters related to atherosclerosis in ovariectomized rats. Tohoku J. Exp. Med., 215(3), 219-226.

Ajiboye, T. O., Aliyu, H., Tanimu, M. A., Muhammad, R. M., Ibitoye, O. B. (2016). Dioscoreophyllum cumminsii (Stapf) Diels leaves halt high-fructose induced metabolic syndrome: Hyperglycemia, insulin resistance, inflammation and oxidative stress. J. Ethnopharm., 192, 471-479.

Akinnuga, A. M., Jeje, S. O., Bamidele, O., Amaku, E. E, Otogo, F. O., Sunday, V. E. (2014). Virgin coconut oil: Remedial effects on renal dysfunction in 
Famurewa, A. C., Nwankwo, O. E., Folawiyo, A. M., Igwe, E. C., Epete, M. A., Ufebe, O. G. (2017). Repeatedly heated palm kernel oil induces hyperlipidemia, atherogenic indices and hepatorenal toxicity in rats: The beneficial role of virgin coconut oil supplementation. Acta Sci. Pol. Technol. Aliment., 16(4), 451-460. http://dx.doi.org/10.17306/J.AFS.2017.0513

diabetic rats. Physiol. J., ID 495926. http://dx.doi. org/10.1155/2014/495926

Alladi, S., Khada, A., Shanmugan, M. (1989). Induction of hypercholesterolemia by simple soil protein with acetate generating amino acid. Nutr. Rep. Int., 40, 893-894.

Ekor, M. (2014). The growing use of herbal medicines: issues relating to adverse reactions and challenges in monitoring safety. Front Pharmacol., 4, 177-186. http:// dx.doi.org/10.3389/fphar.2013.00177

Falade, A. O., Oboh, G., Ademiluyi, A. O., Odubanjo, O. V. (2015). Consumption of thermally oxidized palm oil diets alters biochemical indices in rats. Beni-Suef Univ. J. Basic Appl. Sci., 4, 150-156.

Famurewa, A. C., Ufebe, O. G., Egedigwe, C. A., Nwankwo, O. E., Obaje, G. S. (2017). Virgin coconut oil supplementation attenuates acute chemotherapy hepatotoxicity induced by anticancer drug methotrexate via inhibition of oxidative stress in rats. Biomed. Pharmacoth., 87, 437-442.

Gasevic, D., Frohlich, J., Mancini, G. B., Lear, S. A. (2014). Clinical usefulness of lipid ratios to identify men and women with metabolic syndrome: A cross-sectional study. Lipids Health Dis., 13, 159.

Hur, S. J., Du, M., Nam, K., Williamson, M., Ahn, D. U. (2005). Effect of dietary fats on blood cholesterol and lipid and the development of atherosclerosis in rabbits. Nutr. Res., 25, 925-935. http://dx.doi.org/10.1016/j. nutres.2005.09.016

Ichihara, S. (2013). The pathological roles of environmental and redox stresses in cardiovascular diseases. Environ. Health Prev. Med., 18(3), 177-184.

Jaarin, K., Kamisah, Y. (2012). Repeatedly heated vegetable oils and lipid peroxidation. In A. Catala (Ed.), Biochemistry, genetics and molecular biology (pp. 211-228). [Open access INTECH]. http://dx.doi. org/10.5772/46076

Jaarin, K., Mustafa, M. R., Leong, X.-F. (2011). The effects of heated vegetable oils on blood pressure in rats. Clinics, 66(12), 2125-2132. http://dx.doi.org/10.1590/ S1807-59322011001200020

Jaarin, K., Norliana, M., Kamisah, Y., Nursyafiza, M., Qodriyah, H. S. (2014). Potential role of virgin coconut oil in reducing cardiovascular risk factors. Exp. Clin. Cardiol., 20(8), 3399.

Kalantar, M., Goudarzi, M., Khodayar, M. J., Babaei, J., Foruozandeh, H., Bakhtiari, N., Alidadi, H. (2016). Protective effects of the hydroalcoholic extract of Capparis spinosa $\mathrm{L}$. against cyclophosphamide-induced nephrotoxicity in mice. Jundishapur J. Nat. Pharm. Prod., 11(4), e37240. http://dx.doi.org/10.17795/jjnpp-37240
Kalantari, H., Hemmati, A. A., Bavarsad, N., Rezaie, A., Ahmadi, S. (2014). Effect of topical nanoliposomes of paromomycin on rat liver and kidney. Jundishapur J. Nat. Pharm. Prod., 9(4), e17565.

Kamisah, Y., Periyah, V., Lee, K. T., Noor-Izwan, N., Nurul-Hamizah, A., Nurul-Iman, B. S., ..., Qodriyah, M. S. (2015). Cardioprotective effect of virgin coconut oil in heated palm oil diet-induced hypertensive rats. Pharm. Biol., 53, 9, 1243-1249.

Laguerre, M., Lecomte, J., Villeneuve, P. (2007). Evaluation of the ability of antioxidants to counteract lipid oxidation: existing methods, new trends and challenges. Prog. Lipid. Res., 46(5), 244-282.

Latha, P., Chaitanya, D., Rukkumani, R. (2010). Protective effect of Phyllanthus niruri on alcohol and heated sunflower oil induced hyperlipidemia in Wistar rats. Toxicol. Mech. Meth., 20(8), 498-503.

Marina, A. M., Che-Man, Y. B., Nazimah, S. A., Amin, I. (2009). Antioxidant capacity and phenolic acids of virgin coconut oil. Int. J. Food Sci. Nutr., 60(S2), 114-123.

Mourya, P., Shukla, A., Rai, G., Lodhi, S. (2017). Hypoglycemic and hypolipidemic effects of ethanolic and aqueous extracts from Ziziphus oenoplia (L.) Mill on alloxan-induced diabetic rats. Beni-Suef Univ. J. Basic Appl. Sci., 6, 1-9.

Nair, S. S., Manalil, J. J., Ramavarma, S. K., Suseela, I. M., Thekkepatt, A., Raghavamenon, A. C. (2016). Virgin coconut oil supplementation ameliorates cyclophosphamide-induced systemic toxicity in mice. Hum. Exp. Toxicol., 35(2), 205-212.

National Research Council (1985). Guide for the care and the use of laboratory animals, 20 (pp. 85-123). Bethesda: National Institute of Health.

Nevin, K. G., Rajamohan, T. (2004). Beneficial effects of virgin coconut oil on lipid parameters and in vitro LDL oxidation. Clin. Biochem., 37, 830-835.

Nevin, K. G., Rajamohan, T. (2009). Wet and dry extraction of coconut oil: impact on lipid metabolic and antioxidant status in cholesterol coadministered rats. Can. J. Physiol. Pharmacol., 87, 610-616.

Ng, C.-Y., Leong, X.-F., Masbah, N., Adam, S. K., Kamisah, Y., Jaarina, K. (2014). Heated vegetable oils and cardiovascular disease risk factors. Vascul. Pharmacol., 61, 1-9. http://dx.doi.org/10.1016/j.vph.2014.02.004

Obembe, A. O., Owu, D. U., Okwari, O. O., Antai, A. B., Osim, E. E. (2011). Intestinal fluid and glucose transport in Wistar rats following chronic consumption of fresh or oxidized palm oil diet. ISRN Gastroenterology, ID 972838. http://dx.doi.org/10.5402/2011/972838 
Osim, E. E., Owu, D. U., Etta, K. M. (1996). Arterial pressure and lipid profile in rats following chronic ingestion of palm oil diets. Afr. J. Med. Med. Sci., 25(4), 335-340.

Otuechere, C. A., Madarikan, G., Simisola, T., Bankole, O., Osho, A. (2013). Virgin coconut oil protects against liver damage in albino rats challenged with the anti-folate combination, trimethoprim-sulfamethoxazole. J. Basic Clin. Physiol. Pharmacol. http://dx.doi.org/10.1515/ jbcpp-2013-0059

Owu, D. U., Osim, E. E., Ebong, P. E. (1998). Serum liver enzymes profile of Wistar rats following chronic consumption of fresh or oxidized palm oil diets. Acta Trop., 69(1), 65-73.

Rashid, J. A., Das, S., Kamsiah, J., Qodriyah, H. M., Faizah, O. (2013). Effect of curcumin on aortic changes in ovariectomized rats fed with repeatedly heated soy oil: a preliminary electron microscopic study. Clin. Ter., 164(4), 307-313.

Shastry, C. S., Ambalal, P. N., Himanshu, J., Aswathanarayana, B. J. (2011). Evaluation of effect of reused edible oils on vital organs of Wistar rats. Nitte Univ. J. Health Sci., 1(4), 10-15.

Srivastava, S., Singh, M., George, J., Bhui, K., Saxena, A., Shukla, Y. (2010). Genotoxic and carcinogenic risks associated with the dietary consumption of repeatedly heated coconut oil. Br. J. Nutr., 104(9), 1343-1352.

Srivastava, Y., Semwal, A. D., Majumdar, A. (2016). Quantitative and qualitative analysis of bioactive components present in virgin coconut oil. Cogent Food Agric., 2(1). ID 1164929. http://dx.doi.org/10.1080/23311932.2016. 1164929

Srivastava, Y., Semwal, A. D., Swamy, M. S. (2013). Hypocholesterolemic effects of cold and hot extracted virgin coconut oil (VCO) in comparison to commercial coconut oil: evidence from a male Wistar albino rat model. Food Sci. Biotechnol., 22, 1501-1508.

Subermaniam, K., Saad, Q. H., Das, S., Othman, F. (2014). Virgin coconut oil (VCO) decreases the level of malondialdehyde (mda) in the cardiac tissue of experimental sprague-dawley rats fed with heated palm oil. J. Med. Bioeng., 3(2), 102-106.

Xian, T. K., Omar, N. A., Ying, L. W., Hamzah, A., Raj, S., Jaarin, K., ..., Hussan, F. (2012). Reheated palm oil consumption and risk of atherosclerosis: evidence at ultrastructural level. Evid.-Based Compl. Alter. Med., ID 828170. http://dx.doi.org/10.1155/2012/828170

Yen, P.-L., Chen, B.-H., Yang, F. L., Lu, Y.-F. (2010). Effects of deep-frying oil on blood pressure and oxidative stress in spontaneously hypertensive and normotensive rats. Nutrition, 26, 331-336.

Zhang, Q., Saleh, A. S., Chen, J., Shen, Q. (2012). Chemical alterations taken place during deep-fat frying based on certain reaction products: a review. Chem. Phys. Lipids, 165(6), 662-681. 